\title{
ANTI-CRIME TECHNO WATCH FOR WOMEN SECURITY WEARABLE CHANGING THE WORLD FOR BETTER
}

\author{
Poornima .R J $\mathbf{J}^{1}$, Athira $\mathbf{P ~ K}^{2}$, Monisha Cellace. $\mathbf{I}^{3}$, Sandya $\mathrm{E}^{4}$ \\ ${ }^{1} 8^{\text {th }}$ SEM, Department of Telecommunication, T John Institute of Technology, Bangalore, Karnataka. \\ ${ }^{2} 8^{\text {th }}$ SEM, Department of Telecommunication, T John Institute of Technology, Bangalore, Karnataka. \\ ${ }^{3} 8^{\text {th }}$ SEM, Department of Telecommunication, T John Institute of Technology, Bangalore, Karnataka. \\ ${ }^{4} 8^{\text {th }}$ SEM, Department of Telecommunication, T John Institute of Technology, Bangalore, Karnataka.
}

\begin{abstract}
Presently the most effective global problem which creates questions among the society regarding the security of women against the harassment. The answer would be a thought that strengthens every girl to move alone securely on the streets even in moon hours without the question mark of their safety. This paper brings the technology used to provide security to women. The information about the unique ID and name is located in RFID tag which is inbuilt in wearable. This gets activated with RFID technology. The module designed can be used in the wearable or as a mobileApps, which when activated by panic button or some repetitive shake. The GPS used in this system can track the wretch place. Today's technology at its peak can be used for good cause to reduce these incidents or crime. This unique model also involvesan alarm as an additional safety provision. The ultimate advantage of this system is to provide security to the wretch in any kind of undesirable situation. We believe that this module will make women safe and secure.
\end{abstract}

Keywords: GPS, GSM/GPRS, Wi-Fi, ARM V6, Arm7.

\section{INTRODUCTION}

Over the past few decades the calibre of the women in India has undergone various changes. The history of women in India has been momentous by bringing up the status of the women from the low points of the middle ages to the equal rights. Now in this advanced society women are honoured with respected jobs, but still women are not protected against the violence, harassment and cruel frantic attack against them. The crime rate in the world is increasing day by day. The records of national crime Bureau of India says that for every three minutes a woman is undergoing through a violence physical attack.

Has a woman when compared to men is physically weak and looks for an external help to rescue them. The more simple and effective way to overcome the problem of violence against the women is to track the location of wretch and send the emergency message in need of help to the predetermined contacts. This paper highlights a module provides the users immediate help when they are in danger by sending voice message to their predetermined contacts in the module.

As we proceed we will be looking in to the related works in section 2 .

\section{RELATED WORKS}

A. Ravi SekarYarraboyhu et al [1], has presented an Android App for the safety of women.
Here the victim's phone which is the source device tracks the location of the wretch through GPS which uses $2 \mathrm{G} / 3 \mathrm{G}$ net connection.

From the source device the emergency message containing URL of the place of victim is sent to the predetermined contacts it can be family member or friends and police station.

B. ArchanaNaik et al [2], has presented a normal belt. This system includes a pressure sensor which activates the device when the threshold level of pressure sensor crosses.

It simultaneously perform two operations sends a text message to three contacts for every two minutes by updating the location to three contacts and one to police control room.

In addition this system incorporates an alarm which will get activated and sends a load noise which gives the indication help.

If the above two methods fail to rescue the victim, this system generates an electric shock of low voltage this enables the wretch to escape.

C. Dhruvchand et al [3], have put forth with an aim of providing security for the women.

This mobile application, gives the notification for police control room as well as the friends and family members has and when the phone is shacked. It also sends the picture of the surrounding area. It can also track the location of the victim. 
D. Ramya George et al [4],has presented paper on Intelligent security system consisting of monitoring device.

When there is an insecure environment the system gets activated by the voice command from the 'wretch, as the system is made up of using voice recognization kit. The voice command is pre recorded and provides the necessary prevention measures.

\section{ISSUES IN THE EXISTING PAPER}

Issues concerned with android mobile Apps:

The android App developed for the security of women is not always effective. A wretch in midst of danger cannot completely rely on mobile to stimulate the App. The issues related to mobile battery would fail the complete system irrespective of situation. Android App also includes complications with respect to internal storage when the mobile is concerned.

Issues concerned with women safety belt:

In the present scenario the text message are not very effective as people rarely give importance to text messages. This system provides limited number of contacts ranging from two to four to give indication about the situation. This system also uses shock generator which have the chances of harming the victim by providing shock pulses of few volts. The voice recognizationkit does not provide effective prevention in case the victim is attacked and if the voice command is not recognized due to any interference.

\section{MODULE DEVELOPMENT}

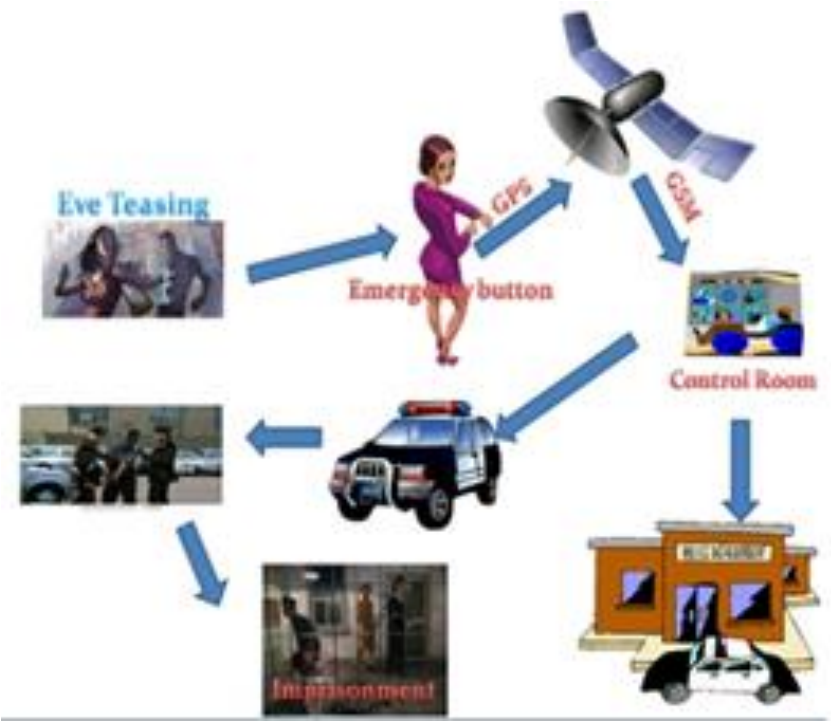

A. Hardware development of process module:

- GSM technology is used. The communication between computer and GSM-GPRS system is established by using GSM/GPRS module. Higher data transmission rate is enabled by using GPRS which is the extension of GSM.

- Raspberry pi 2 model B+ uses a quad core arm7 processor with the arm v7 instruction set. Both GPU and CPU are inbuilt. It is interacted and controlled by using python and other programming language.

- GPS: All forms of information about the geographical location are displayed and analysed. The activated GPS tracks the location of the victim.

B. Software development of process module:

- Python: It is an interpreter based language. It has a wide library support for pyserial, pygps etc. It can act has a mediator between devices and operating system.

- Embedded Linux: The raspberry pi is built upon the ARM V6 architecture, which runs on embedded Linux, so we choose the official operating system "Raspbian Jessie" - a debian based Linux operating system.

- CGPS: Command line GPS, a tool to receive the GPS values (latitude, longitude etc.) and fed to python for further processing.

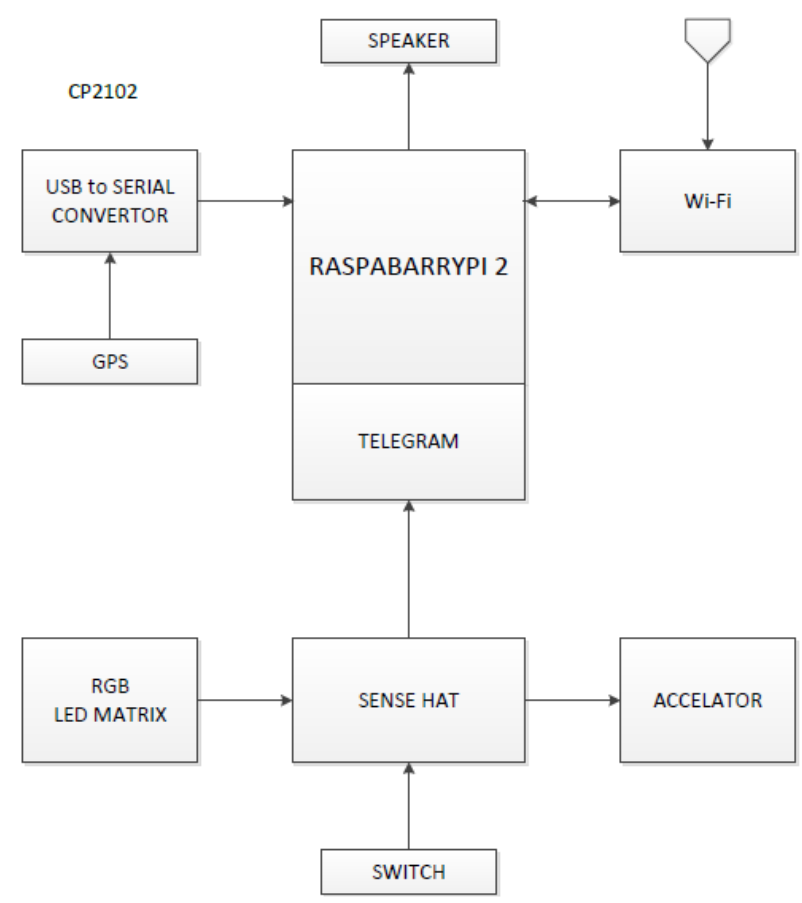

Fig 1: Block diagram

\section{FUTURE WORK}

We have come across many system designed for women security purpose but still these have drawbacks and hence the enhancement in the existing systems is been done has follows.

A system is designed to get activated with repetitive shakes (moment). The intensity of the movement of device is predetermined or pre-set. This system has enhanced features once the system gets activated the location of the victim is tracked by GPS module and emergency telegraph message is replaced with the WhatsApp text. The message when interacted with the WhatsApp group, it is delivered 
to many contacts in the group. So the possibility of getting rescued is high. And this can be easily implemented with the permission from WhatsApp developer.

The module size is made compact and the required feature in the android security App is used in the module. The module can be used in a normal wrist watch or in a pendent with panic button. This module alone is used for the complete rescue process; there is no need of using mobile, which is normally impractical to be handled in emergency situations.

With these features a panic alarm is used and it is designed to get activated with secure states, the sound produced by this ideal unique panic alarm is different. It makes siren sound along with LED lights designed for particular RGB colours.

The siren sound made by alarm can provide two way securities by creating assumption of arrival of rescue forces and indication of crime in that location to the public.

As we have seen in this system which are already existing the geographical location of victim is sent only once to the predefined contacts but when we consider the practical situation, when the places of the victim changes by taking the victim to another place in that case the message is continuously being sent for every five minutes to the preset contacts. Because of this high technology enhancement, the women can easily be rescued.

\section{CONCLUSION}

By taking the advantages of the existing technologies for the security of women and combining our ideas of utilizing the telegram messaging with this technology we have made enhancement in the system which can effectively provide security in an adverse conditions.

This module provides the confidence among the women in the country to strongly protect themselves in any hypercritical situations.

\section{REFERENCE}

[1]

Ravi

sekharyarrabother, Bramarambikathota,"ABHAYA: An Android app for the safety of women". IEEE INDICON 20151570191849

[2] Prof. BasavarajChougula, ArchanaNaik, Monika MoryPriyapatil and Priyanka Das "Smart Girls Security System", International Journal of application or Innovation in Engineering and Management volume 3, Issue 4, April 2014

[3] Drub Chand, Sunil Kayak, Kathie S. Bhat, Shivani Parikh, Yuvraj Singh, AmitaAjithKamath "A mobile Application for women's safety: WoS App", 978-1-47998641-5/15/\$ 31.00 C 2015 IEEE

[4] Remya George, AnjalyCherian. V, Annet Antony, HarshaSebestian, Mishal Antony, Rosemary Babu. T, “An Intelligent security system for violence against women in public places", International Journal of engineering and Advanced Technology(ITEAT)ISSN: 2249-8958, volume3, Issue-4, April 2014

\section{BIOGRAPHIES}

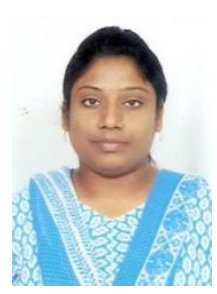

Poornima R J (TJIT)

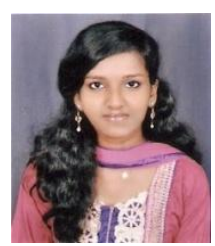

Athira P K (TJIT)

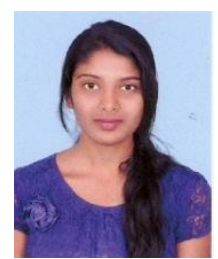

MonishaCellace I

(TJIT)

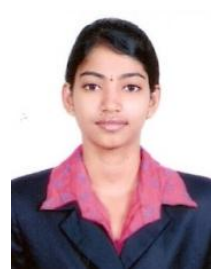

Sandya E (TJIT) 